\title{
Effects of Cloud Parameterization on Radiation and Precipitation: A Comparison Between Single-Moment Microphysics and Double-Moment Microphysics
}

\author{
Seoung Soo Lee ${ }^{1, *}$ and Leo J. Donner ${ }^{2}$ \\ ${ }^{I}$ NOAA/ESRL, Chemical Sciences Division, Boulder, Colorado, USA \\ ${ }^{2}$ Geophysical Fluid Dynamics Laboratory, Princeton University, Princeton, New Jersey, USA
}

Received 3 July 2010, accepted 3 March 2011

\begin{abstract}
This study compares a single-moment microphysics scheme to a double-moment microphysics scheme using four observed cases of a mesoscale cloud system. Previous studies comparing a single-moment microphysics scheme to a doublemoment microphysics scheme have focused on microphysical processes or overall dynamics, precipitation and morphology of cloud systems. However, they have not focused on how the different representation of microphysical processes between a single- and double-moment microphysics scheme affects precipitation. This study shifts its focus from that of previous studies to the effect of the different representation of microphysics on precipitation. In addition, this study examines the effect of the different representation of microphysical processes on different radiation budgets between single- and double-moment microphysics schemes.

The temporal evolution of precipitation simulated by a single-moment microphysics scheme is significantly different from that by a double-moment microphysics scheme in this study. This is mostly due to different physical representations of key processes (i.e., autoconversion, saturation, and nucleation). Also, a simulation by a single-moment microphysics scheme results in different radiation budgets compared to a double-moment microphysics scheme. More reflection of incident solar radiation in a simulation with a double-moment microphysics scheme than that with a single-moment microphysics scheme is simulated.
\end{abstract}

Key words: Single-moment microphysics, Double-moment microphysics, Precipitation

Citation: Lee, S. S. and L. J. Donner, 2011: Effects of cloud parameterization on radiation and precipitation: A comparison between single-moment microphysics and double-moment microphysics. Terr. Atmos. Ocean. Sci., 22, 403-420, doi: 10.3319/TAO.2011.03.03.01(A)

\section{INTRODUCTION}

In bulk microphysics schemes, the prediction of both the mass and number of droplets and crystals as advected quantities enables the prediction of their sizes, for an assumed form of the particle size distribution. Such schemes are referred to as the "double-moment microphysics." Schemes predicting only the mass of the particles and (generally) diagnosing the number of cloud particles from prescribed sizes are referred to as the "single-moment microphysics."

The immediate radiative impact of clouds depends on the size as well as the mass of their particles. The par-

\footnotetext{
* Corresponding author

E-mail:Seoung.Soo.Lee@noaa.gov
}

ticle size also influences cloud lifetime and spatial extent through the preferential sedimentation of larger particles and through the coagulation of cloud particles to form precipitation. Hence, the double-moment microphysics can provide more rigorous solutions for aerosol-cloud interactions, a source of the large uncertainties in the prediction of climate changes, than single-moment microphysics: the prediction of the particle number in the double-moment microphysics enables the explicit simulation of the effect of changing aerosol properties on the size of cloud particles (and thus on radiation and precipitation), while the prescribed size of single-moment microphysics does not vary with the changing aerosol properties. Although some of single-moment schemes predict the size by using empirical relations between aerosol and cloud-particle numbers, this 
prediction is not able to consider aerosol properties as explicitly as double-moment schemes. Thus, this prediction is not able to provide solutions for aerosol-cloud interactions as rigorously as double-moment schemes.

In the last few years, some general circulation models (GCMs) and cloud-system resolving models (CSRMs) migrated from single-moment microphysics to doublemoment microphysics (Lohmann et al. 2007; Morrison and Gettelman 2008; Salzmann et al. 2010). This represents efforts toward the development of more physically-based and self-consistent cloud models to better assess the effect of aerosol on clouds and thus climate. Changes in the microphysics parameterization (from single-moment microphysics to double-moment microphysics) lead to different cloud simulations, with different radiative cloud properties and precipitation which in turn affect hydrological and energy circulations. It is desirable to analyze how these changes affect cloud simulations and an agreement between the simulations and observation through studies which compare the single-moment microphysics with the double-moment microphysics as is performed by Morrison et al. (2009) and Straka et al. (2005, 2007). Morrison et al. (2009) focused on the effect of the different representation of rain evaporation between a double-moment microphysics and a singlemoment microphysics on the structure of a squall line. They examined this effect on the dynamics and morphology of convective and stratiform regions in a squall line, which is a mesoscale cloud system driven by deep convection. Straka et al. $(2005,2007)$ examined differences in the conservation of hydrometeor number concentrations between a doublemoment microphysics and a single-moment microphysics. In this paper, we also compare double-moment microphysics with single-moment microphysics for simulated mesoscale cloud systems; however, our focus shifts from that of Morrison et al. (2009) and Straka et al. (2005, 2007). We focus on the identification of the role of different physical representations of key microphysical processes in differences in simulated precipitation between double-moment microphysics and single-moment microphysics. Also, we examine the effect of different physical representations of microphysical processes (between a double-moment microphysics and single-moment microphysics) on radiation. The identification of the role the different representations of key processes play in precipitation is partly motivated by the fact that more sophisticated microphysics schemes generally raise computational costs. Examining how the different representations of key processes affect simulations and focusing on the improvement of their physical representations should lead to an efficient and accurate parameterization for a better simulation of precipitation. Also, this study evaluates single- and double-moment microphysics via a comparison with observed precipitation and radiation. The comparison of the different schemes with observation reveals how different representations of physical processes af- fect the agreement between the simulations and observation. This identifies weaknesses and strengths of each scheme, which can be useful for the development of microphysics parameterization in terms of a better simulation of precipitation and radiation.

\section{CSRM}

\subsection{Dynamics, Turbulence, and Radiation}

For numerical experiments, the Weather Research and Forecasting (WRF) model (Michalakes et al. 2001) is used as a nonhydrostatic compressible model. Detailed equations of the dynamical core of WRF are described by Klemp et al. (2007). Hong and Pan's (1996) scheme, which includes non-gradient flux for heat and moisture and calculates vertical eddy diffusion, is used for delineating the planetary boundary layer. For radiation, a simplified version of the Geophysical Fluid Dynamics Laboratory (GFDL) radiation code is incorporated into the WRF (Freidenreich and Ramaswamy 1999). Effective sizes of cloud liquid and cloud ice are predicted using assumed size distributions (see section 2.2 for assumed size distributions).

\subsection{Double-Moment Microphysics}

To represent microphysical processes, the WRF is modified to use the double-moment bulk representation of Phillips et al. (2007). The size distribution of cloud liquid and cloud ice $(\mathrm{x}=\mathrm{c}, \mathrm{i})$ obeys a gamma distribution:

$n\left(D_{x}\right)=n_{x, 0} D_{x}^{p_{x}} \exp \left(-\lambda_{x} D_{x}\right)$

where $D_{x}$ is the equivalent spherical diameter and $n\left(D_{x}\right) d D_{x}$ is the number concentration (or density) of particles in the size range $d D_{x}$. Also, $\lambda_{x}$ is the slope, $n_{x, 0}$ is the intercept, and $p_{x}$ is the shape parameter of the distribution:

$$
\begin{aligned}
& \lambda_{x}=\left[\frac{\Gamma\left(4+p_{x}\right) \rho_{x} \frac{\pi}{6} n_{x}}{\Gamma\left(1+p_{x}\right) q_{x}}\right]^{\frac{1}{3}} \\
& n_{x, 0}=\left(n_{x} \rho_{a}\right) \lambda_{x}^{1+p_{x}} / \Gamma\left(1+p_{x}\right)
\end{aligned}
$$

Here, $\Gamma$ is the Gamma function, $\rho_{x}, n_{x}$ and $q_{x}$ are the particle bulk density, number mixing ratio (particle number per unit air mass, which is in $\mathrm{kg}^{-1}$ ) and mass mixing ratio, respectively. $\rho_{a}$ is air density. $p_{i}$ and $p_{c}$ are set to unity and 3.5 , respectively, based on field experiments described in Phillips et al. (2007). The linearized scheme that predicts the in-cloud supersaturation and diffusional growth of cloud particles is adopted. This linearized scheme solves equations for the evolution of the water-vapor mixing ratio and 
temperature by considering diffusional growth of both liquid and solid hydrometeors and is described in more detail in Appendix in Phillips et al. (2007). For precipitable hydrometeors (snow, graupel, and rain) the exponential form of the size distribution in the scheme used by Lin et al. (1983) is applied. The sedimentation of cloud ice is taken into account. The microphysics is the single-moment, predicting hydrometeor mass only, for snow, graupel, and rain and the double-moment, predicting hydrometeor mass and number both, for cloud liquid and cloud ice. Autoconversion of droplets to rain is performed in the same manner as presented by Eq. (50) in Lin et al. (1983), except that the threshold on the cloud-liquid mixing ratio is replaced by the product of the predicted droplet number mixing ratio $\left(\mathrm{kg}^{-1}\right)$ and the mass of a droplet of a critical size (in diameter), $D_{w, \text { auto }}$ $(20 \mu \mathrm{m})$. Once cloud-liquid mixing ratio exceeds the threshold, rain is formed through this autoconversion scheme; see Lin et al. (1983) for details. Accretion of cloud liquid and cloud ice by precipitation represents, to a degree, the dependence of collision efficiency on their size following Phillips et al. (2007); see the section $2 \mathrm{~h}$ in Phillips et al. (2007) for details.

Droplet nucleation follows the nucleation parameterization of Ming et al. (2006). In their parameterization, an aerosol can take any form of size, distribution and chemical composition. Critical super-saturation and critical radius are calculated considering the aerosol's chemical composition, based on the Köhler theory. Lohmann and Diehl's (2006) parameterizations, taking into account the dependence of ice nuclei (IN) activation on dust and black carbon (BC) aerosol mass concentration, are used for contact, immersion, and condensation-freezing activation of IN. For deposition nucleation, the parameterization of Möhler et al. (2006), calculating the fraction of dust activated, is implemented [see Lee et al. (2008) for details of ice-particle nucleation].

Homogeneous aerosol (haze particles) freezing is assumed to occur instantaneously when a size and temperature dependent critical super-saturation with respect to ice for freezing is exceeded. Graphically, this phenomenon is represented by considering the predicted size distribution of unactivated aerosols. A "look-up" table for the critical supersaturation ratio at which cloud condensation nuclei $(\mathrm{CCN})$ freezes homogeneously is based on the theory proposed by Koop et al. (2000). Homogenous droplet freezing is performed by instantaneous conversion of supercooled cloud droplets to cloud ice at temperatures colder than $-36^{\circ} \mathrm{C}$. In the present study, the fraction by number of cloud droplets that are frozen homogeneously just above the $-36^{\circ} \mathrm{C}$ level is parameterized with a 3D look-up table considering supersaturation. This procedure is identical to that elucidated by Phillips et al. (2007).

Secondary production of ice occurs by the HalletMossop process of rime splintering (Hallet and Mossop 1974) and involves 350 ice splinters emitted for every mil- ligram of rimed liquid at $-5.5^{\circ} \mathrm{C}$. The number of splinters per milligram of rime liquid is linearly interpolated to zero between -3 and $-8^{\circ} \mathrm{C}$.

\subsection{Single-Moment Microphysics}

A single-moment microphysics used in Phillips and Donner (2006) is adopted by the WRF for the comparison with the double-moment microphysics. This single-moment microphysics predicts the mass of all types of cloud hydrometeors but not their number. This single-moment microphysics is the version provided by Lin et al. (1983) microphysics scheme. It has five classes of hydrometeors (cloud liquid, cloud ice, snow, graupel and rain) and includes sedimentation of cloud ice as in the double-moment microphysics adopted in this study. As in the double-moment microphysics, automatic conversion of droplets to rain is performed in the same manner as presented by Eq. (50) in Lin et al. (1983). However, the threshold is fixed in this singlemoment microphysics while the threshold is predicted in the double-moment microphysics (as described in the section 2.2). No dependence on the particle size is considered for the accretion of cloud liquid and cloud ice by precipitation in the single-moment microphysics due to the absence of the particle-number and -size prediction, whereas the dependence is considered in the double-moment microphysics.

The saturation adjustment scheme proposed by Lord et al. (1984) is included, replacing the prediction of super-saturation in the double-moment microphysics. In this adjustment scheme, water vapor exceeding the saturation level is immediately condensed or deposited. In this scheme, water vapor below the saturation level is assumed to immediately reach the saturation level through the evaporation or sublimation of hydrometeors, if there are available hydrometeors. Also, the initial formation of cloud particles (i.e., nucleation) is diagnosed by the saturation adjustment.

Due to the absence of the particle-number prediction, the effective particle size diameter of a cloud droplet is assumed to be $20 \mu \mathrm{m}$, and that of cloud ice is given by empirical functions of height (McFarquhar et al. 1999). The homogeneous freezing of all supercooled droplets and rain is performed at $-36^{\circ} \mathrm{C}$ or below. However, the homogeneous freezing is assumed not to occur above $-36^{\circ} \mathrm{C}$ in the singlemoment microphysics due to the absence of the super-saturation prediction; the parameterization for freezing above $-36^{\circ} \mathrm{C}$ requires the predicted super-saturation. In our study, the freezing occurs above $-36^{\circ} \mathrm{C}$ in the double-moment microphysics adopted here as described in the section 2.2. The homogeneous freezing of haze particles is not taken into account in the single-moment microphysics but is calculated in double-moment microphysics, which is enabled by the super-saturation prediction. The freezing of haze particles requires the predicted super-saturation as described in the section 2.2 
Rime-splintering is not considered in single-moment microphysics but is considered in double-moment microphysics due to predictability of the particle number; see section 2.2 for details of the splintering. Except for differences between single-moment microphysics and double-moment microphysics, described in this section, single-moment microphysics is identical to double-moment microphysics in this study.

\section{INTEGRATION DESIGN}

\subsection{Control Run}

The WRF coupled with double-moment microphysics (described in section 2.2) is used for the control run. The model domain has 3 dimensions. The horizontal and vertical domains are $168 \times 168 \mathrm{~km}^{2}$ and $20 \mathrm{~km}$, respectively, to cover a mesoscale cloud system. The horizontal grid length is $500 \mathrm{~m}$ and the vertical grid length is $300 \mathrm{~m}$. Arakawa $\mathrm{C}$-grid staggering scheme is used. Periodic boundary conditions are set on horizontal boundaries, and heat and moisture fluxes are prescribed at the surface. To initiate clouds, random water-vapor perturbations are imposed at the first time step following Lee et al. (2008).

For the control run, Atmospheric Radiation Measurement (ARM) sub-case A (2330 UTC 26 June - 2330 UTC 30 June 1997) observations provide the initial and large-scale forcings of temperature and humidity. Large-scale forcings represent synoptic conditions in this situation. Initial temperature and humidity profiles are shown in Fig. 1. The large-scale advective cooling rates associated with the major precipitation event of sub-case A reach its maximum of $1.8 \mathrm{~K} \mathrm{~h}^{-1}$ at $7 \mathrm{~km}$, while the large-scale advective moistening rates have maxima of $0.4 \mathrm{~g} \mathrm{~kg}^{-1} \mathrm{~h}^{-1}$ at 2 and $5 \mathrm{~km}$. The zonal wind component has a moderate low-level shear for subcase A. More detailed descriptions of large-scale forcings of the ARM sub-case A can be found in Xu et al. (2002). The details of the procedure for applying large-scale forcings are described in Lee et al. (2008).

The aerosol mass profiles were extracted from a version of the GFDL AM2 (2004) nudged by NCEP re-analysis with aerosol chemistry. These extracted mass-concentration profiles, averaged over a one-day period, were obtained at $\left(36.61^{\circ} \mathrm{N}, 97.49^{\circ} \mathrm{W}\right)$ on 26 June 1997 . These averaged vertical profiles act as background aerosol-mass profiles for the control run and are shown in Fig. 2. The background aerosol mass varies in the vertical domain and is homogeneous in the horizontal domain. Sulfate, organic and salt aerosols are assumed to act only as $\mathrm{CCN}$ and to have tri-modal lognormal size distributions. The mode diameter and standard deviation of the distributions, as well as the partitioning among modes, are assumed to follow Whitby's (1978) values for clean continental air mass and not to vary spatiotemporally. Dust and BC aerosols are assumed to act only as IN with uni-modal lognormal size distributions. For BC and dust, mode diameter and standard deviation are from Seinfeld and Pandis's (1998) values for remote continental areas and

(a)

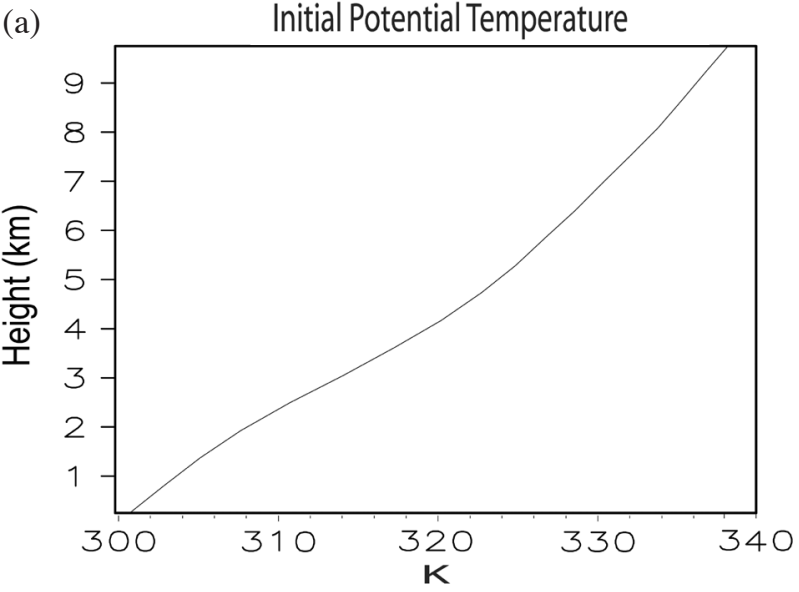

(b)

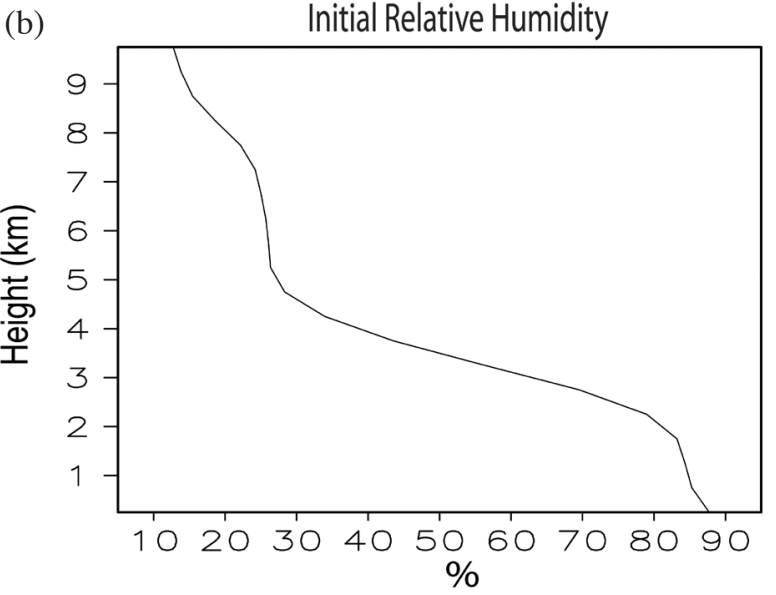

Fig. 1. Vertical profiles of the initial conditions for the ARM sub-case A: (a) potential temperature and (b) relative humidity.

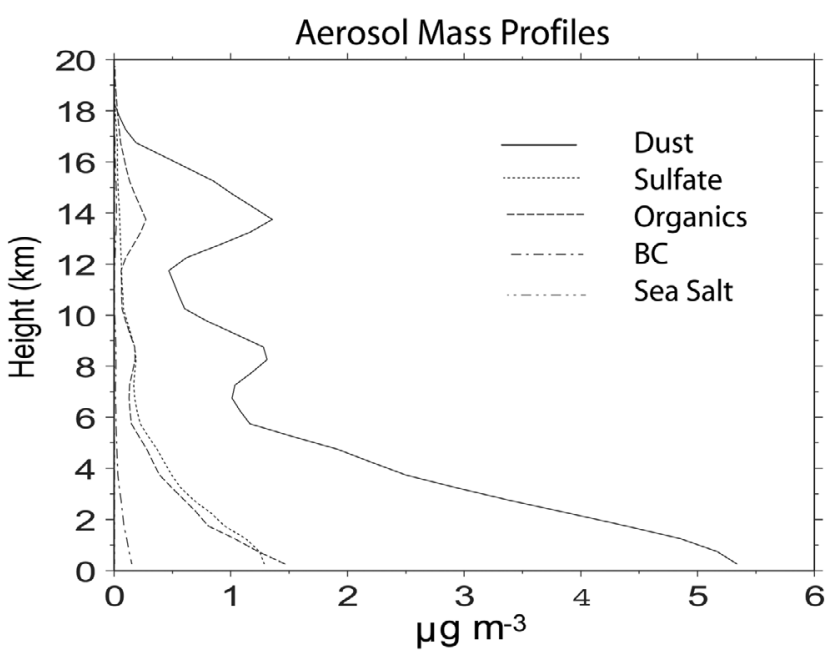

Fig. 2. Vertical profiles of aerosol species for the ARM sub-case A. Salt is present, but its values are less than $0.01 \mu \mathrm{g} \mathrm{m}^{-3}$. 
also assumed not to vary spatiotemporally. Within clouds, aerosols are advected, diffused, and depleted by nucleation. Depending on predicted aerosol mass within a cloud, the total aerosol number for each aerosol species varies and is reset to the background value at all levels outside cloud. The aerosol number concentration in each bin of the size spectrum is determined based on aerosol mass, an assumed aerosol-particle density, and the assumed log-normal size distribution at each grid point. Initially aerosol-mass mixing ratio is everywhere set equal to its background value. The background aerosol-mass concentration for all aerosol species in each aerosol size mode are assumed not to vary during time integration since the variation of the extracted aerosols from GFDL AM2 was not significant on the date of simulations.

\subsection{Sensitivity Tests}

Five experiments are performed using the same model setup as in the control run but with different microphysics. The first experiment, which is performed with the WRF coupled with the single-moment microphysics (described in section 2.3), is compared to the control run and examines differences in simulated cloud properties (e.g., precipitation and radiation) between single- and double-moment microphysics. This first experiment is referred to as the "singlemoment run." The comparison between the control and single-moment runs accompanies another four experiments which examine the role of different physical representations of key processes in different precipitation between singleand double-moment microphysics.

In the single-moment microphysics in this study, only the autoconversion parameterization considers cloud droplet number concentration (CDNC). CDNC for the autoconversion parameterization in the double-moment microphysics varies spatiotemporally but it is assumed to be a fixed value in the single-moment microphysics due to the absence of the number prediction. The comparison of the double-moment microphysics (the control run) with the single-moment microphysics (the single-moment run) requires a consistency in the background aerosol properties as well as background thermodynamic conditions. In the single-moment microphysics, CDNC in the autoconversion parameterization acts as a proxy for the aerosol number concentration. Though it is not possible to be perfectly consistent in aerosol properties between the schemes due to the intrinsic differences, a rough consistency in aerosol number concentration can be made. The CDNC predicted by the double-moment microphysics can be fed into the autoconversion parameterization in the single-moment microphysics. This enables the singlemoment run to represent a similar level of aerosol number concentration to that in the control run. Since a constant $\mathrm{CDNC}$ is assumed in the single-moment microphysics, incloud average CDNC from the double-moment microphys- ics (the control run), which is $170 \mathrm{~cm}^{-3}$, is adopted for the autoconversion parameterization in the single-moment run. For this, the average CDNC is assumed to represent the average level of aerosol number concentration in the control run. For the calculation of in-cloud averaged values (in the simulations with the double-moment microphysics), it is needed to determine the grid points in cloud. Grid points are assumed to be in cloud if the number concentration and volume-mean size of droplets is typical for clouds and fogs ( $1 \mathrm{~cm}^{-3}$ or more, $1 \mu \mathrm{m}$ or more; Pruppacher and Klett 1978). To calculate the in-cloud average of a variable of interest, first, the conditional average over the grid points in cloud is obtained at each time step; the conditional average is the arithmetic mean of the variable over collected grid points in cloud (grid point in clear air is excluded from the collection). Then, those conditional averages are collected and averaged over time to obtain the in-cloud average; only time steps with non-zero conditional averages are included in the collection over time.

Although there are a number of differences which can contribute to different simulations of precipitation between single- and double-moment microphysics, two differences are key candidates: a difference in the saturation scheme and that in the treatment of autoconversion. Autoconversion affects the initiation and duration of precipitation. The saturation scheme controls condensation, and, thereby, the amount of precipitation. To investigate the role these two key processes play in different precipitation, four more experiments in addition to the control and single-moment runs are conducted.

The model setup of the first experiment of these four more experiments is the same as in the control run but the CDNC in the autoconversion parameterization does not vary spatiotemporally and is set to the same value as in the single-moment run. Thus, the autoconversion threshold does not vary in this experiment and is referred to as the "double-threshold run." A comparison among the control run, single-moment run and double-threshold run identifies the role of the different treatment of autoconversion in making precipitation differences between the single-moment and double-moment microphysics.

The model setup of the second experiment of the four more experiments is the same as in the double-threshold run but the super-saturation prediction is replaced by the saturation adjustment used in the single-moment run and is referred to as the "double-saturation run." In the doublesaturation run, the mass concentration of nucleated cloud particles is diagnosed by the saturation adjustment, replacing the explicit nucleation parameterizations in the doublethreshold run. In the double-saturation run, the number concentration of cloud particles produced from nucleation is diagnosed by dividing the diagnosed initial (or nucleated) cloud-mass concentration by an assumed particle mass of newly formed droplet or ice crystal. In the double-saturation 
run, the diagnosed initial (or nucleated) cloud mass by the saturation adjustment results in a cloud-liquid and cloud-ice mass which formed at gird points where the cloud-liquid and cloud-ice mixing ratios are zero, respectively. The diagnosed number concentration from the saturation adjustment is fed to processes associated with the particle number (e.g., homogeneous freezing of droplets) in the double-moment microphysics. Hence, in the double-saturation run, cloud processes associated with the prediction of cloud particle number except for nucleation operate in the same manner as in the double-threshold run.

The third experiment of the four more experiments is the same as the double-saturation run but with auto-conversion threshold which is treated in the same manner as in the control run. This experiment is referred to as the "doublesaturation-only run." The double-saturation-only run is to isolate the effect of the different representation of nucleation and saturation on different precipitation between the singlemoment and double-moment microphysics by a comparison among the control, single-moment, double-saturation, and double-saturation-only runs.

The last experiment, referred to as the "double-other run" is performed. The purpose of this experiment is to further elucidate the importance of the key processes in determining differences in precipitation between the singlemoment and double-moment microphysics. The detailed purpose and description of the double-other run are given in the next section, and a brief description of this run (and all the other runs) is shown in Table 1 which summarizes differences among the runs.

Also, some of the above-mentioned simulations are repeated for the ARM sub-cases B (0000 UTC 7 July - 0000 12 July 1997) and C (0000 UTC 12 July - 000017 July 1997), which are described in Lee et al. (2008) and Xu et al. (2002), and for the Tropical Warm Pool International Cloud Experiment (TWP-ICE) campaign (1200 UTC 23 January 1200 UTC 25 January 2006), described in May et al. (2008) and Fridlind et al. (2009). This is to confirm and support

Table 1. Differences in the design of simulation among the single-moment, control, double-threshold, double-saturation, double-saturation-only and double-other runs.

\begin{tabular}{|c|c|c|c|c|c|c|}
\hline Simulation & $\begin{array}{l}\text { Microphysics } \\
\text { Scheme }\end{array}$ & $\begin{array}{l}\text { Cloud Particle } \\
\text { Number }\end{array}$ & $\begin{array}{l}\text { CDNC for } \\
\text { Autoconversion }\end{array}$ & $\begin{array}{l}\text { Saturation } \\
\text { Scheme }\end{array}$ & $\begin{array}{l}\text { Nucleation } \\
\text { Scheme }\end{array}$ & $\begin{array}{l}\text { Other processes } \\
\text { (i.e., accretion, } \\
\text { homogeneous freezing } \\
\text { and rime splintering) }\end{array}$ \\
\hline Single-moment & Single-moment & No prediction & Fixed $\left(170 \mathrm{~cm}^{-3}\right)$ & $\begin{array}{l}\text { Saturation } \\
\text { adjustment }\end{array}$ & $\begin{array}{l}\text { Diagnosis of initial } \\
\text { mass of cloud } \\
\text { particles }\end{array}$ & $\begin{array}{l}\text { No size dependent col- } \\
\text { lection efficiency for } \\
\text { accretion, homogeneous } \\
\text { freezing of all cloud liquid } \\
\text { at }-36^{\circ} \mathrm{C} \text { or below, no } \\
\text { homogeneous freezing of } \\
\text { haze particles and no rime } \\
\text { splintering }\end{array}$ \\
\hline Control & Double-moment & Predicted & Predicted & $\begin{array}{l}\text { Prediction of } \\
\text { supersaturation }\end{array}$ & $\begin{array}{l}\text { Explicit predic- } \\
\text { tion of number } \\
\text { and mass of cloud } \\
\text { particles }\end{array}$ & $\begin{array}{l}\text { Size dependent collection } \\
\text { efficiency for accretion, } \\
\text { explicit homogeneous } \\
\text { freezing of haze and cloud } \\
\text { particles, and the consider- } \\
\text { ation of rime splintering }\end{array}$ \\
\hline Double-threshold & Double-moment & Predicted & Fixed $\left(170 \mathrm{~cm}^{-3}\right)$ & $\begin{array}{l}\text { Prediction of } \\
\text { supersaturation }\end{array}$ & $\begin{array}{l}\text { Explicit predic- } \\
\text { tion of number } \\
\text { and mass of cloud } \\
\text { particles }\end{array}$ & Same as in the control run \\
\hline Double-saturation & Double-moment & $\begin{array}{l}\text { Diagnosed (for nucle- } \\
\text { ation) /Predicted (for } \\
\text { the other processes) }\end{array}$ & Fixed $\left(170 \mathrm{~cm}^{-3}\right)$ & $\begin{array}{l}\text { Saturation } \\
\text { adjustment }\end{array}$ & $\begin{array}{l}\text { Diagnosis of initial } \\
\text { mass and number } \\
\text { of cloud particles }\end{array}$ & Same as in the control run \\
\hline Double-saturation-only & Double-moment & $\begin{array}{l}\text { Diagnosed (for nucle- } \\
\text { ation) /Predicted (for } \\
\text { the other processes) }\end{array}$ & Predicted & $\begin{array}{l}\text { Saturation } \\
\text { adjustment }\end{array}$ & $\begin{array}{l}\text { Diagnosis of initial } \\
\text { mass and number } \\
\text { of cloud particles }\end{array}$ & Same as in the control run \\
\hline Double-other & Double-moment & Predicted & Predicted & $\begin{array}{l}\text { Prediction of } \\
\text { supersaturation }\end{array}$ & $\begin{array}{l}\text { Explicit predic- } \\
\text { tion of number } \\
\text { and mass of cloud } \\
\text { particles }\end{array}$ & $\begin{array}{l}\text { Same as in the single- } \\
\text { moment run }\end{array}$ \\
\hline
\end{tabular}


findings from the ARM sub-case A. These repeated simulations are described in section 4.1.

\section{RESULTS}

\subsection{Precipitation}

Figure 3a shows the time series of the area-averaged precipitation rate for the control and single-moment runs and the observed precipitation rate during the entire simulation period in the ARM sub-case A. Figure 4 shows contours of mass mixing ratios of cloud liquid and cloud ice obtained around the occurrence of a maximum precipitation rate in the middle of a north-south direction in the control run for the ARM sub-case A. These contours indicate cloud types are mainly cumulonimbus (reaching the tropopause) and high-level cumulus whose tops are $\sim 6-7 \mathrm{~km}$ at mature stages of cloud development as observed. The precipitation rate in the single-moment run shows a better agreement with the observed precipitation rate in the first precipitation event around 2330 UTC on 27 June. The peak and temporal spread of the precipitation rate in the single-moment run are in better agreement with the observed precipitation rate than those in the control run in the first event (Fig. 3a). Nevertheless, the single-moment run generally shows an agreement with observed precipitation not as good as the control run in the second and third precipitation events around 2330 UTC on 28 June and 1130 UTC on 30 June, respectively. In the second precipitation event, the single-moment run and the control run both show higher precipitation peaks than the observed peak. However, the peak in the single-moment run is $\sim 4$ times higher than the observed peak, while the peak in the control run is $\sim 1.5$ times higher than the observed peak (Fig. 3a). This generally leads to a better agreement between the control run and observation than that between the single-moment run and observation in the second event (Fig. 3a). In the third precipitation event where more than $80 \%$ of the total precipitation occurs, the single-moment run shows a narrower temporal spread of precipitation and a peak two times higher than those in observation and the control run. The control run shows a much closer temporal spread of precipitation and the precipitation peak to the observed spread and peak than the single-moment run in the third event (Fig. 3a). Therefore, precipitation in the control run generally shows a better agreement with observed precipitation in the second and third precipitation events where $\sim 90 \%$ of the total precipitation occurs. Hence, overall, precipitation in the control run can be considered to be in a better agreement with observations than the single-moment run during the entire simulation period.

Figure $3 \mathrm{~b}$ shows the time series of the area-averaged precipitation rates for the double-threshold and single-moment runs, and observed precipitation rate during the entire simulation period in the ARM sub-case A. There are significant differences in the precipitation rate between the double- threshold and single-moment runs in the first and second precipitation events where two cases of shallow convection whose tops are around $5-6 \mathrm{~km}$ at its mature stage. In the third precipitation event (when the maximum precipitation rate occurs during the whole simulation period), a case of deep convection whose tops reach the tropopause as shown in Fig. 4, the difference in the precipitation rate between the double-threshold and single-moment runs is barely visible. This demonstrates that when the auto-conversion in the double-moment microphysics is treated in the same manner as in the single-moment microphysics, the double-moment microphysics results in similar precipitation to that in the single-moment microphysics for deep convection.

Figure $3 c$ shows the time series of the area-averaged precipitation rate for the double-saturation and single-moment runs during the entire simulation period in the ARM sub-case A. Figure $3 \mathrm{c}$ indicates that when the saturation and nucleation schemes and auto-conversion treatment in the double-moment microphysics are replaced with those in the single-moment microphysics, the precipitation evolution with the double-moment microphysics becomes similar to that with the single-moment microphysics for all precipitation events. Hence, the sensitivity of differences in precipitation to the different representation of processes other than saturation, nucleation and auto-conversion between the single- and double-moment microphysics is likely to be negligible. To confirm this, the control run is repeated but with identical treatments of processes to those in the singlemoment run except for saturation, nucleation, and auto-conversion. The accretion of cloud particles by precipitation and homogeneous freezing of cloud liquid are treated in the same manner as in the single-moment run. The dependence of the accretion of cloud particles by precipitation on the particle size is neglected and homogeneous freezing of cloud liquid occurs only at $-36^{\circ} \mathrm{C}$ or below in this repeated run. Also, the homogeneous freezing of haze particles and the secondary ice production (rime-splintering) are neglected in this repeated run as in the single-moment run. Again, this repeated run is referred to as a "double-other run." Figure 3d shows the time series of the area-averaged precipitation rate for the single-moment run and double-other run in the ARM sub-case A. Figure $3 \mathrm{~d}$ shows that there are significant differences in the temporal variation of precipitation between the single-moment and double-other runs throughout the entire simulation period. These differences are similar to those between the control run and the single-moment runs shown in Fig. 3a, indicating that changes in the representation of processes other than saturation, nucleation and autoconversion have a negligible impact on precipitation. This and the substantial difference in precipitation between the double-saturation run and the control run (Figs. 3a and c) confirm that the sensitivity of precipitation to the different treatments of auto-conversion, saturation, and nucleation is much stronger than that of the other processes. 
While the representation of auto-conversion, saturation and nucleation plays important roles in the different precipitation between the single-moment and double-moment microphysics, comparisons here identified a dependence of the roles of the representation on a type of convection. The difference in the representation of auto-conversion affects the precipitation from deep convection much more than that from shallow convection. As shown in a comparison between Figs. $3 \mathrm{a}$ and $\mathrm{b}$, the auto-conversion difference affects the third precipitation event with deep convection strongly and its effect on the first and second events with shallow convection is negligible as compared to that on the third event.

The double-saturation run is repeated by allowing CDNC for auto-conversion to be predicted as in the auto- conversion treatment in the control run. This repeated run is referred to as "double-saturation-only run;" see Table 1 for the description of the double-saturation-only run. The difference in the precipitation between the double-saturation-only run and single-moment run in the third event is similar to that between the control run and single-moment run as shown in Figs. 3a and e. However, the difference in the precipitation between the double-saturation-only run and the single-moment run in the first and second events is negligible, which is similar to differences in the first and second events between the single-moment run and doublesaturation run shown in Figs. 3c and e. The double-saturation-only, double-saturation, and the double-threshold runs (as compared to the single-moment and control runs) demonstrate that the precipitation with a shallow convec-
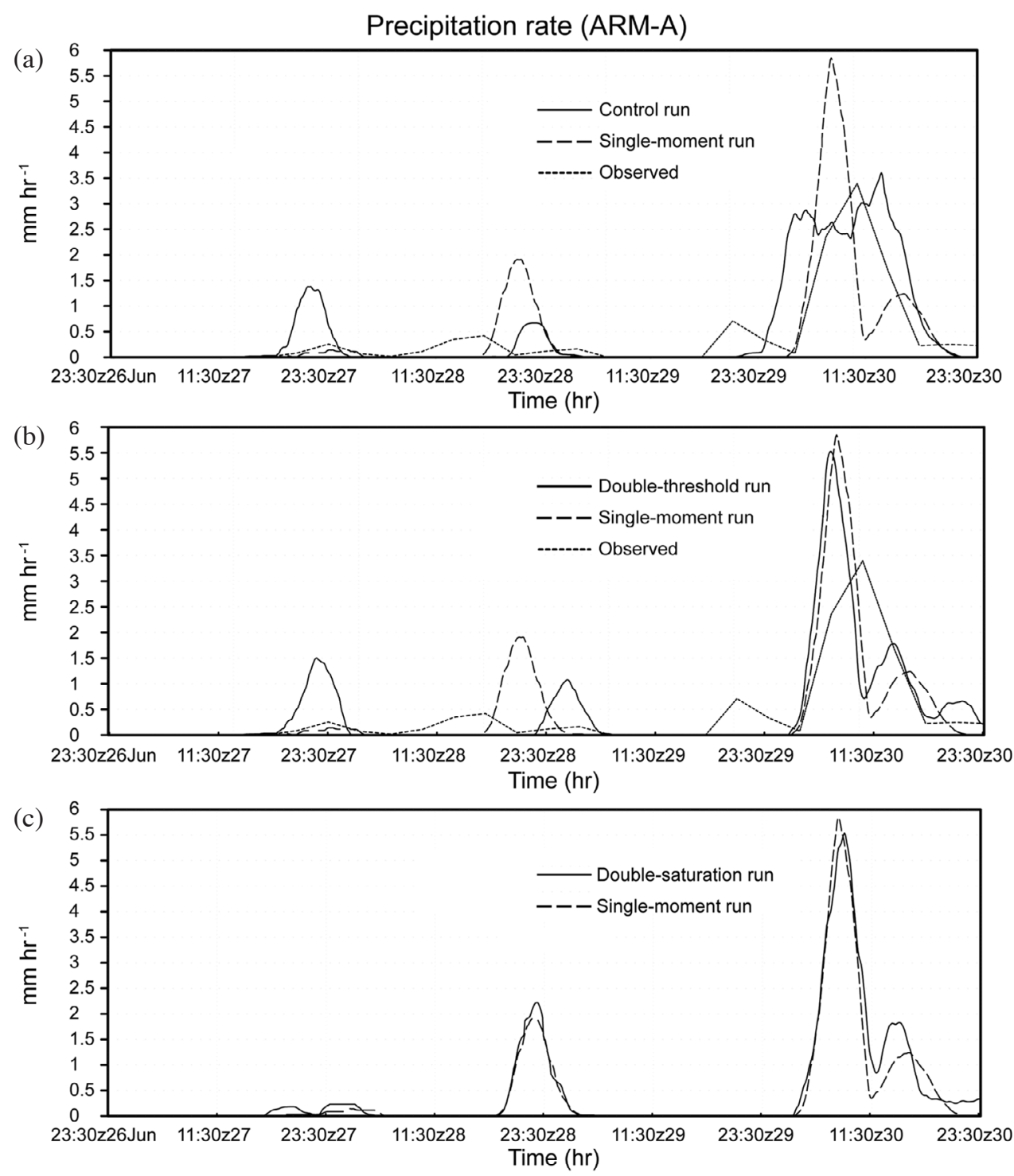

Fig. 3. Time series of area-averaged precipitation for the ARM sub-case A. (a) is for the control and single-moment runs; (b) for the double-threshold and single-moment runs; (c) for the double-saturation and single-moment runs; (d) for the double-other and single-moment runs; (e) for the doublesaturation-only and single-moment runs. For comparison, observed precipitation is included in (a) and (b). 

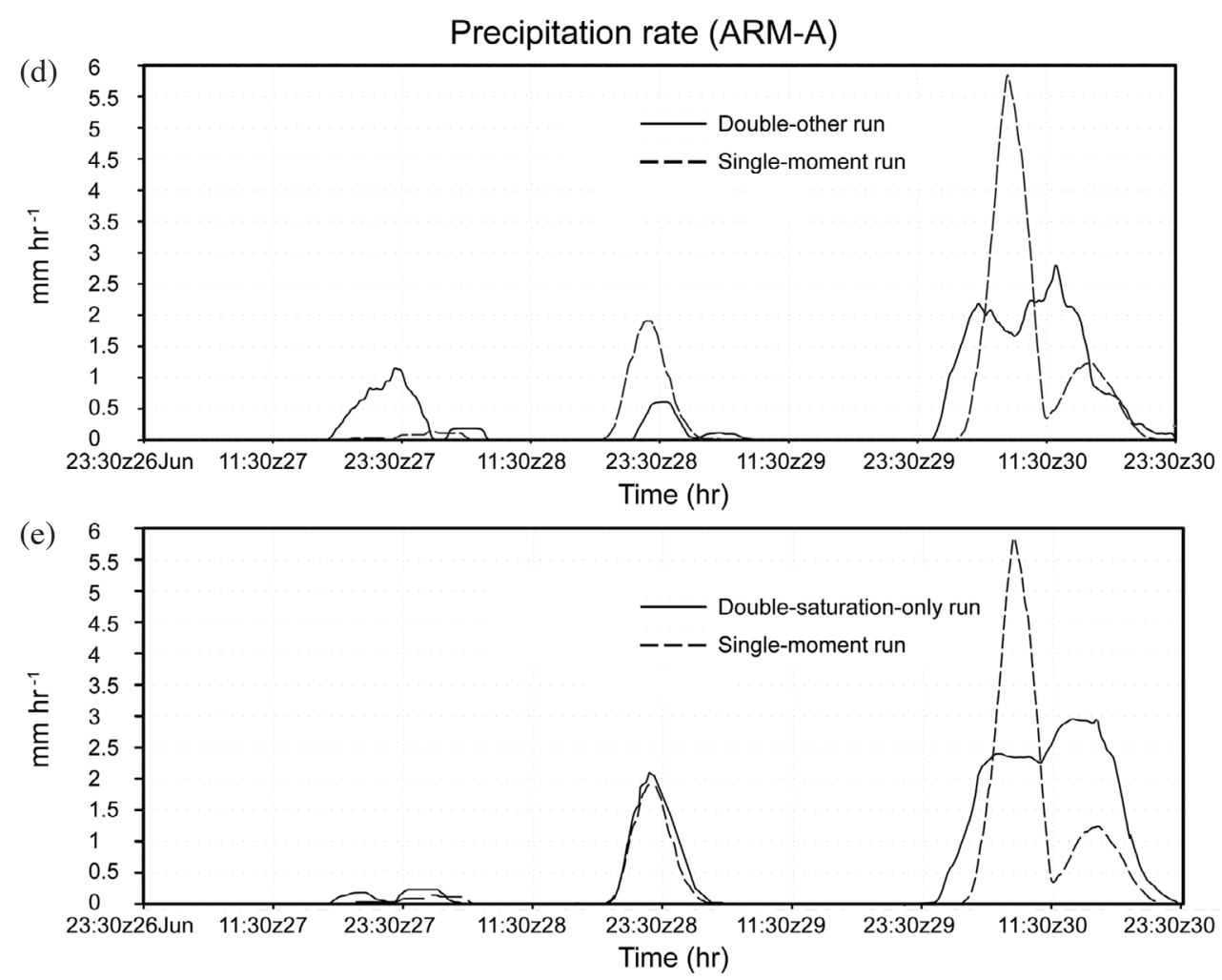

Fig. 3. (Continued)

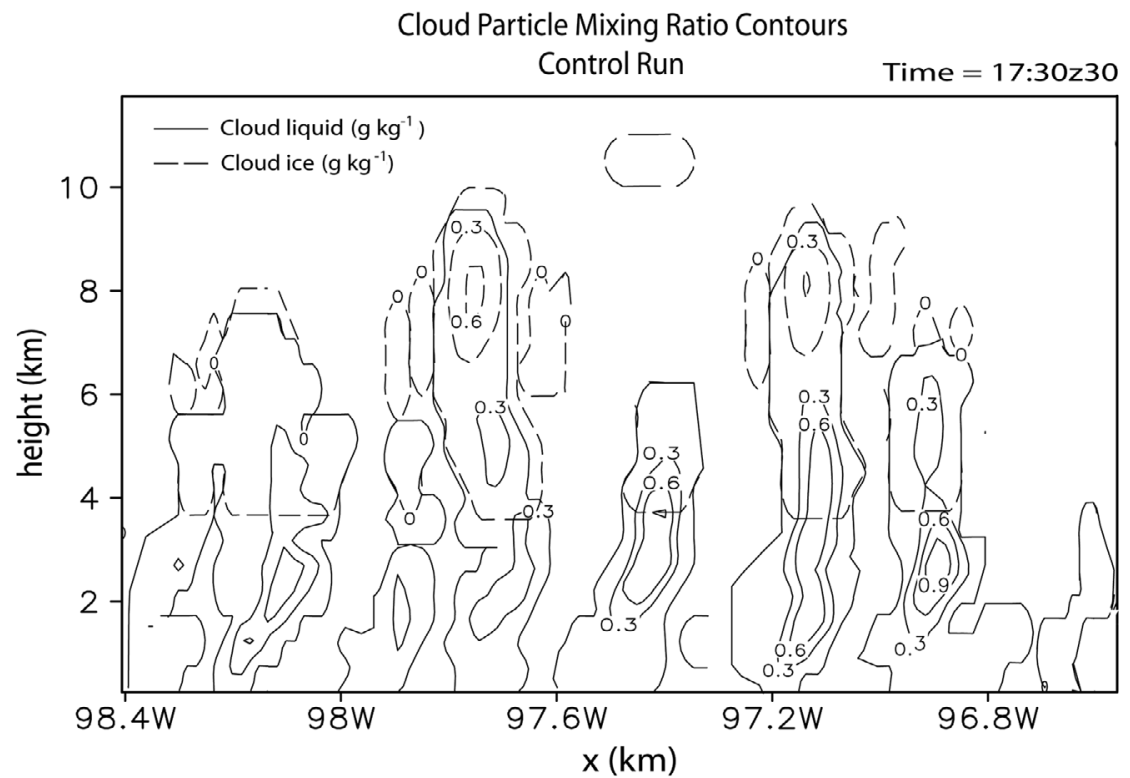

Fig. 4. Contours of cloud liquid (solid line) and cloud ice (dashed line) $\left(\mathrm{g} \mathrm{kg}^{-1}\right)$ at the time of the occurrence of maximum precipitation rate (1730 GMT 30 June) in the middle of a north-south direction in the control run for the ARM sub-case A. Contour starts at $0 \mathrm{~g} \mathrm{~kg}^{-1}$ and contour interval is $0.3 \mathrm{~g} \mathrm{~kg}^{-1}$.

tion is mostly affected by how the saturation and nucleation are represented. They also confirm that the effect of how the auto-conversion is treated on precipitation with shallow convection can be considered negligible.
To confirm the above findings from simulations for the ARM-A case, simulations are repeated for the ARM-B and $-\mathrm{C}$ sub-cases and the TWP-ICE case. The ARM-B and -C cases (the TWP-ICE case) are cases of a mesoscale cloud 
system driven by a shallow (deep) convection. The same CSRM and model setup as for the ARM sub-case A are applied to these repeated simulations except that the ARM sub-cases $\mathrm{B}$ and $\mathrm{C}$ and the TWP-ICE observations provide large-scale forcing, surface fluxes and background aerosols. Figures 5, 6, and 7 show the repeated control, single-moment, double-threshold, double-saturation-only and doubleother runs for the ARM-B and -C and the TWP-ICE cases. These figures show that the double-moment microphysics is better consistent with observation than the single-moment microphysics as simulated in the ARM-A case; see the comparison among the control run, single-moment run, and observation. As seen in these figures, for shallow convection in the ARM-B and -C cases, which is indicated by a precipitation rate $<2.5 \mathrm{~mm} \mathrm{hr}^{-1}$, the saturation and nucleation play a most important role in making precipitation differences between the single- and double-moment microphysics. The double-threshold run in these cases does not decrease the difference between the single- and double-moment microphysics, whereas the double-saturation-only run decreases the difference dramatically. For deep convection in the TWP-ICE case, which is indicated by the maximum precipitation rate $>10 \mathrm{~mm} \mathrm{hr}^{-1}$, the treatment of auto-conversion plays a critical role in the precipitation differences. The double-threshold run does decrease the differences between the single- and double-moment microphysics significantly, whereas the double-saturation-only run does not decrease the differences in the TWP-ICE case. Also, the double-other and single-moment runs for each of the ARM-B and -C and the TWP-ICE cases result in the precipitation differences which are similar to those between the single-moment and control runs. This indicates that processes other than saturation, nucleation and auto-conversion play a negligible role in making the precipitation differences. Hence, simulations from these three additional cases demonstrate that the findings from the ARM-A case are reasonably robust.

\subsection{Radiation (ARM-A Case)}

The contribution of rain, snow and hail to radiation budgets is negligible as compared to that of cloud liquid and cloud ice. This negligible contribution of rain, snow and hail is because their particle sizes are generally larger than the radiation wavelengths. Hence, this study focuses only on the role of cloud liquid and cloud ice in radiation among hydrometeors. The size and water path of cloud liquid and cloud ice play important roles in determining the effects of clouds on radiative fluxes. Hence, one or both of simulated size and path of cloud particles are compared to the observation to evaluate simulated impacts of clouds on radiation for the ARM sub-case A, depending on the availability of observed data. The domain-averaged liquid-water path (LWP) in the control run is $51 \mathrm{~g} \mathrm{~m}^{-2}$. This LWP is within $\sim 10 \%$ of the observed LWP $\left(55 \mathrm{~g} \mathrm{~m}^{-2}\right)$ for the ARM-
A case. Thus, clouds in the control run can be considered to be reasonably well simulated for the calculation of radiation. The LWP is observed by the microwave radiometer and corrections are made to eliminate the contamination by raindrops on the instrument as described in Liljegren (1994). The comparisons for the size of cloud liquid and the size and path of cloud ice are not viable here, since the 1997 ARM observation does not provide those data, though more recent ARM observations after the year 2000 started to provide those data.

The time- and area-averaged radiative fluxes from the control and single-moment runs are shown with observed fluxes in Table 2 for the ARM-A case. The upward top of atmosphere (TOA) component of shortwave radiation flux (SW) in the single-moment run is $\sim 25 \mathrm{~W} \mathrm{~m}^{-2}$ less than that in the control run. Figure 8 a shows that generally the timeand area-averaged mass concentration of cloud liquid is smaller in the single-moment run than in the control run. Figure $8 \mathrm{~b}$ shows the prescribed effective size of cloud droplets in the single-moment run is larger than the explicitly calculated in-cloud average size in the control run. The incloud average of a variable is obtained at each of levels to construct the vertical distribution of the in-cloud average in this study; see section 3.2 for details of how to obtain the in-cloud average. For the time- and area-averaged value of a variable, simply all the grid points over all of the time steps are collected with no conditions at each of levels. Then, an arithmetic mean value is obtained from these collected grid points for each of levels, which construct the vertical distribution of the time- and area-averaged values. The smaller cloud-liquid mass decreases the reflectivity of clouds and, hence, favors less reflection of incident solar radiation on clouds in the single-moment run as opposed to the control run. Also, for a given cloud-liquid mass, a larger size of cloud-liquid particles provides a decreased surface area of cloud-liquid particles, which decreases the reflectivity of clouds and thus the reflection of incident solar radiation on clouds in the single-moment run. Hence, the size and mass of cloud liquid shown in Figs. 8a and b tend to produce less reflection of solar radiation in the single-moment run than in the control run.

Figure $8 \mathrm{c}$ shows the vertical profile of the time- and area-averaged cloud-ice mass. The averaged cloud-ice mass is larger in the control run than in the single-moment run. The larger cloud-ice mass increases the reflectivity of clouds and, hence, tends to increase the reflectivity of incident solar radiation on clouds in the control run than in the single-moment run. The in-cloud averaged generalized effective size of cloud ice is larger in the control run than in the single-moment run where the generalized size is prescribed as a function of air temperature following McFarquhar et al. (1999) (Fig. 8d). For a given cloud-ice mass, a smaller size of ice particles provides an increased surface area of ice particles, which increases reflectance of clouds 
Precipitation rate (ARM-B)
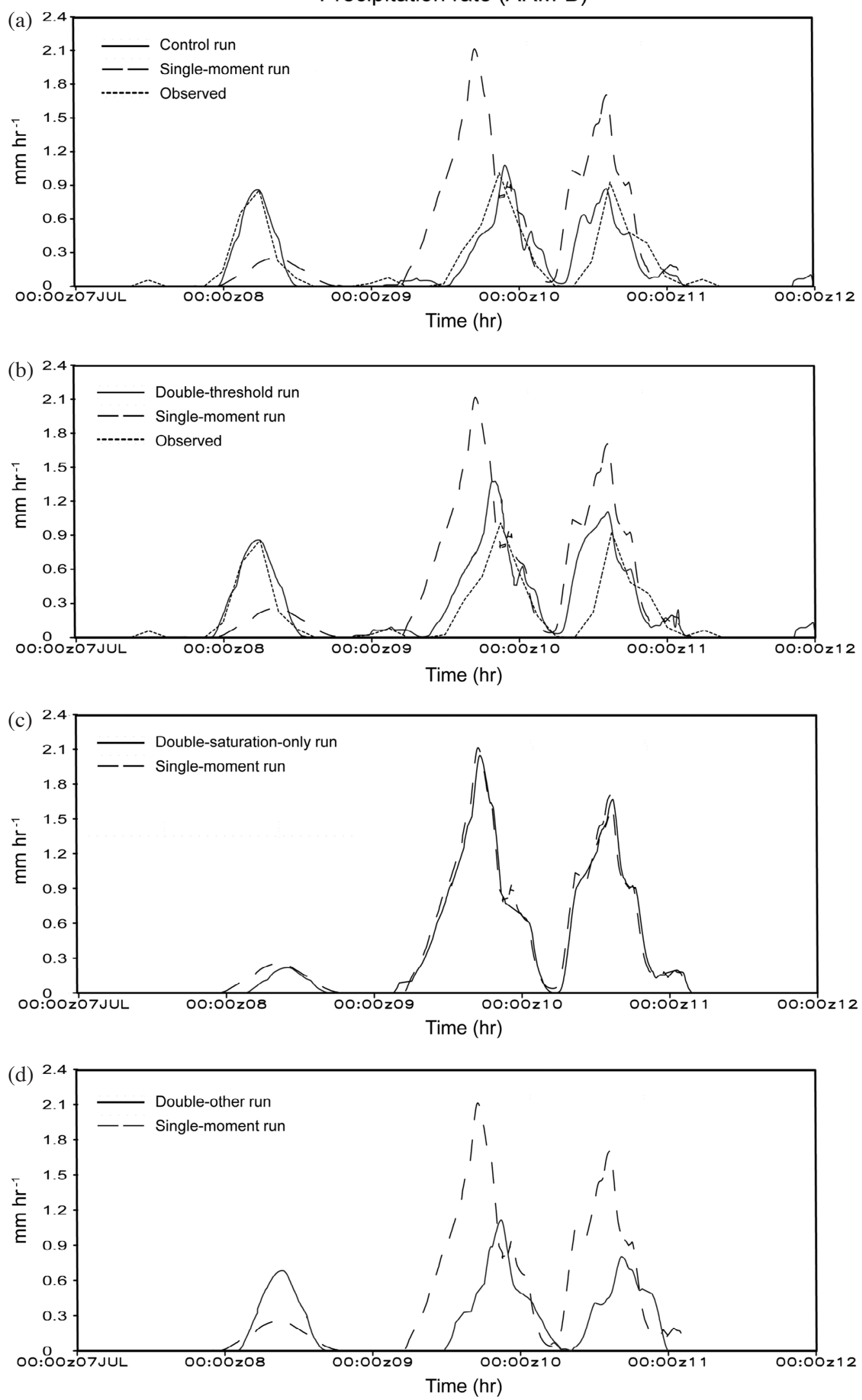

Fig. 5. (a), (b), (c) and (d) are the same as (a), (b), (e) and (d) in Fig. 3, respectively, but for the ARM sub-case B. 

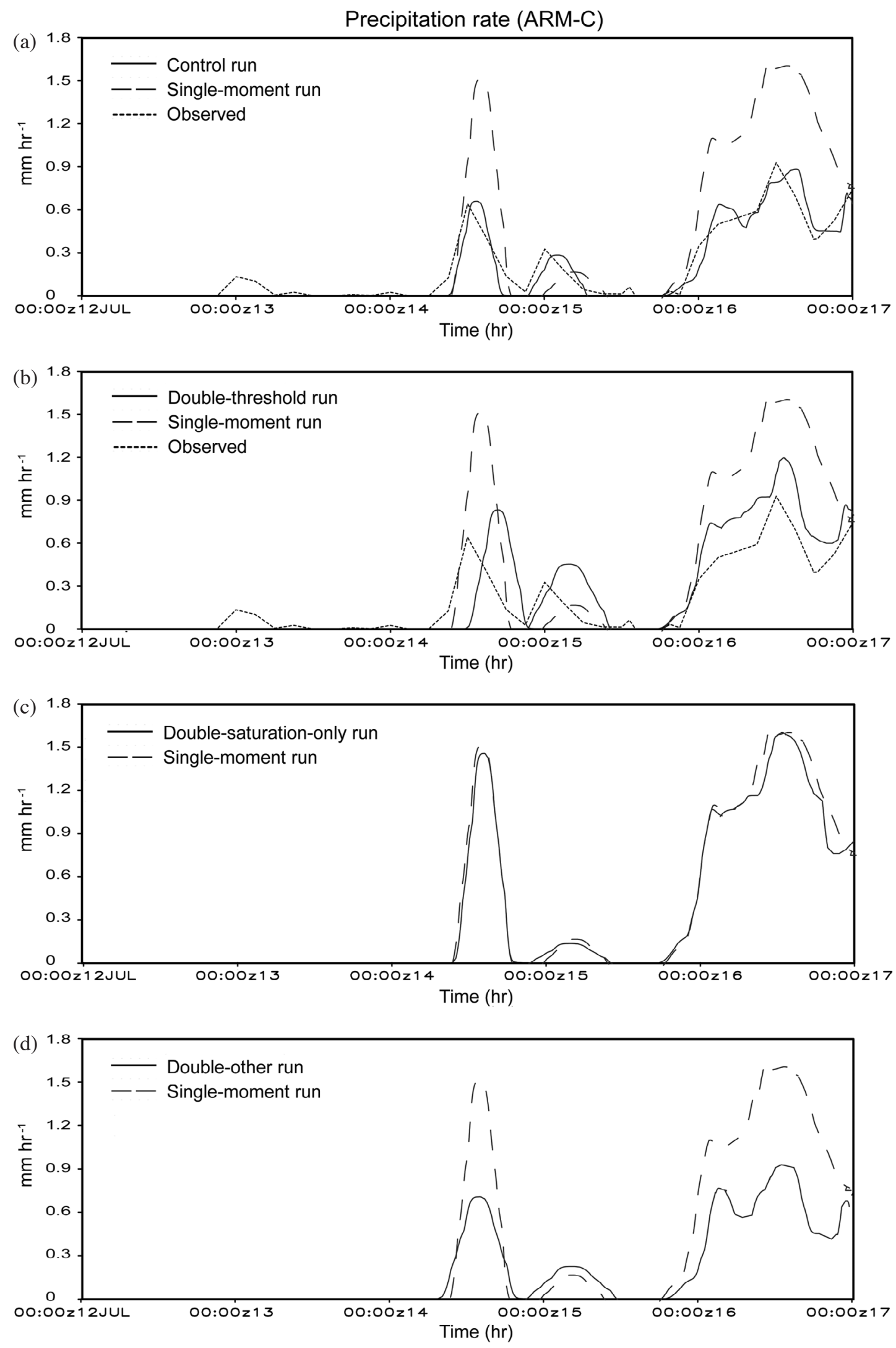

Fig. 6. (a), (b), (c) and (d) are the same as (a), (b), (e) and (d) in Fig. 3, respectively, but for the ARM sub-case C. 

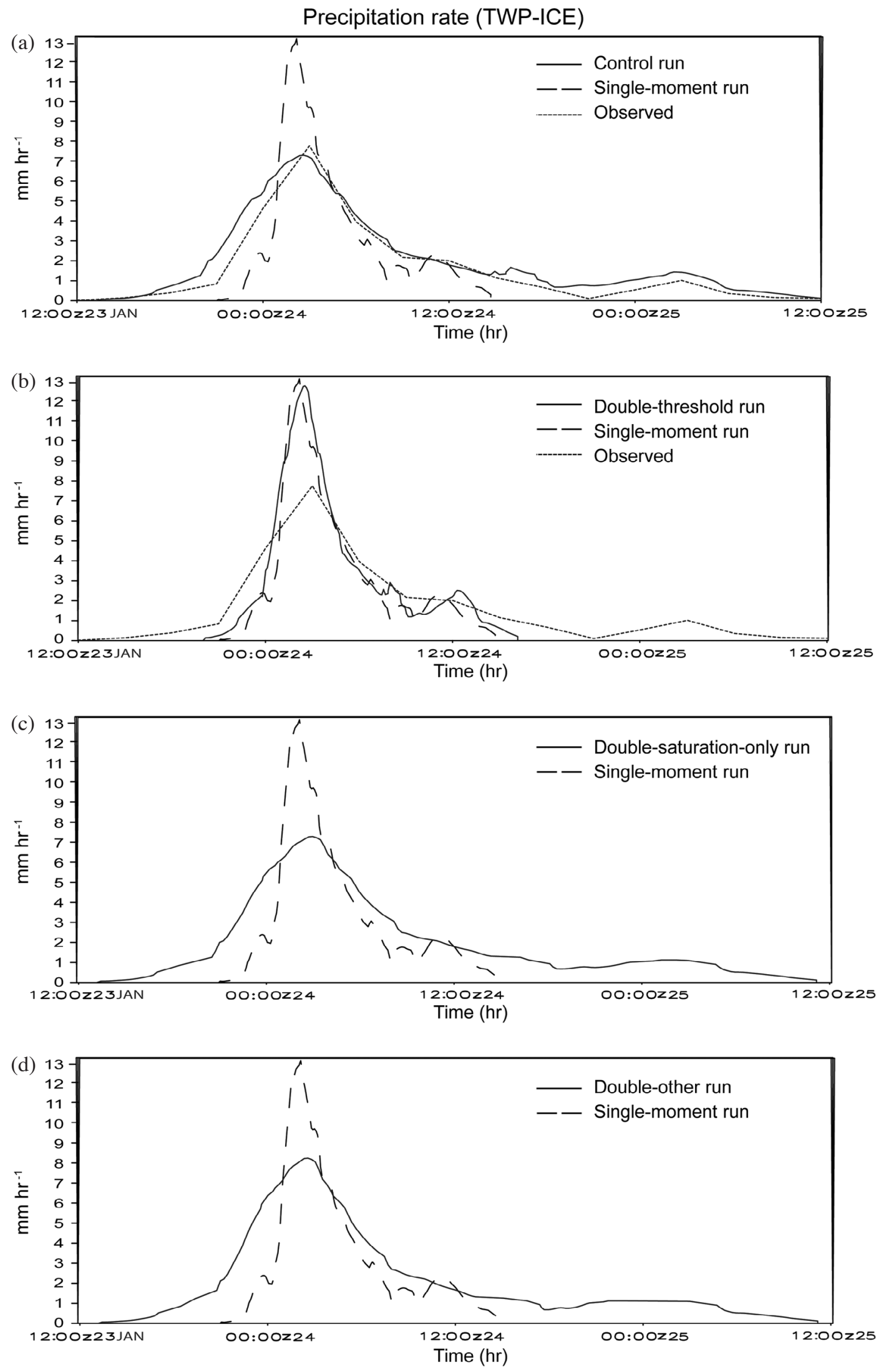

Fig. 7. (a), (b), (c) and (d) are the same as (a), (b), (e) and (d) in Fig. 3, respectively, but for the TWP-ICE case. 
Table 2. Time and area-averaged top of atmosphere (TOA) and surface (SFC) shortwave flux (SW) and longwave flux $(\mathrm{LW})\left(\mathrm{W} \mathrm{m}^{-2}\right)$ for the control and single-moment runs and observation for the ARM sub-case A.

\begin{tabular}{cccccc}
\hline \multirow{2}{*}{$\begin{array}{c}\text { Simulation } \\
\text { /observation }\end{array}$} & \multicolumn{2}{c}{ SW } & \multicolumn{2}{c}{ LW } \\
\cline { 2 - 3 } \cline { 5 - 6 } & TOA Upwards & SFC downwards & & TOA Upwards & SFC Downwards \\
\hline Control & 120.92 & 288.07 & & 257.10 & 370.17 \\
Single-moment & 95.32 & 317.71 & & 273.42 & 268.93 \\
Observed & 111.65 & 279.44 & & 260.23 & 397.12 \\
\hline
\end{tabular}

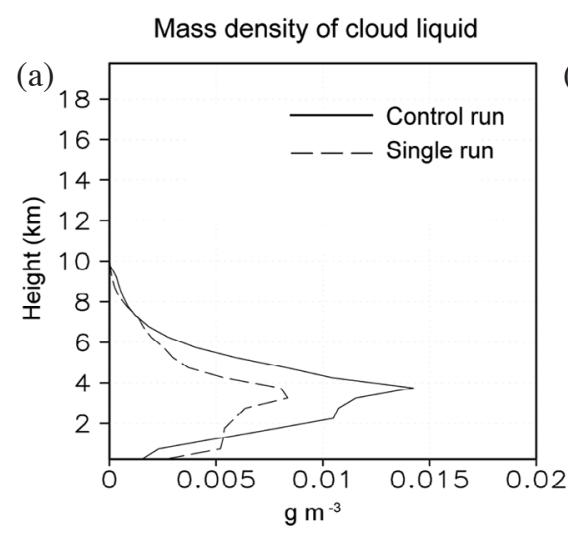

Generalized effective size of cloud ice

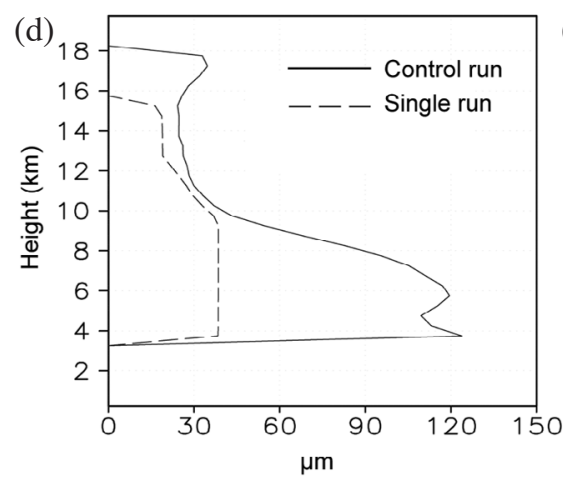

Effective size (diameter) of cloud liquid

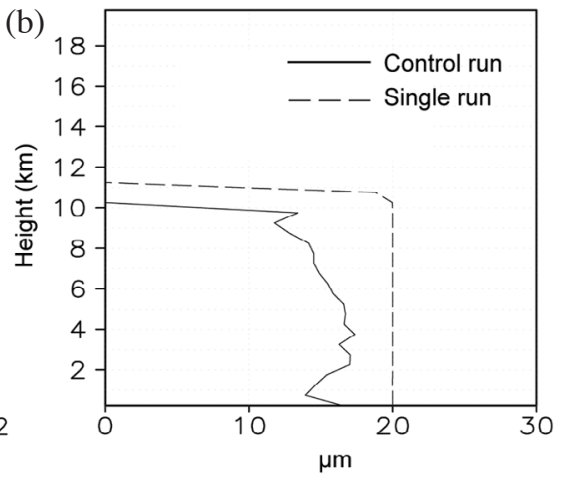

Upward shortwave flux

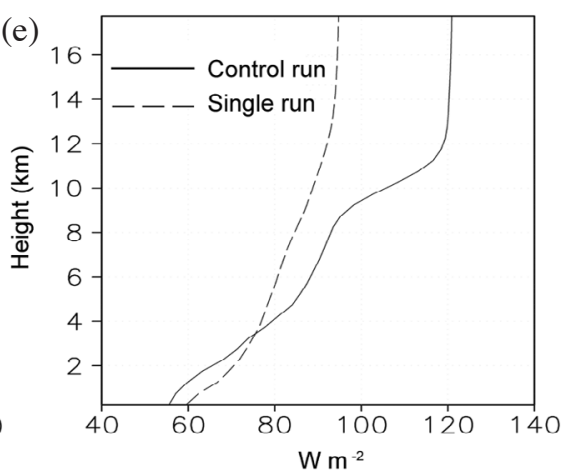

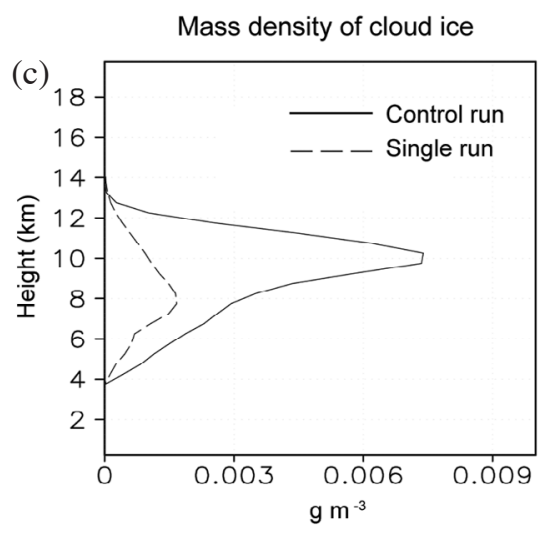

Radiative heating

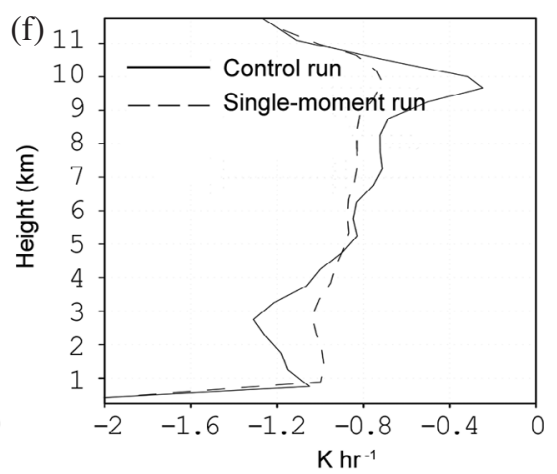

Fig. 8. Vertical distribution of (a) and (c) the time- and area-averaged mass density, (b) and (d) in-cloud average effective size, (e) the time- and area-averaged upward SW, and (f) the time- and area-averaged radiative heating rate for the control and single-moment runs for the ARM sub-case A. (a) and (b) are for cloud liquid, and (c) and (d) are for cloud ice.

and thus reflection of incident solar radiation on clouds. Hence, the smaller size of cloud ice favors more reflection of solar radiation in the single-moment run than in the control run. However, the enhanced cloud-ice and cloud-liquid mass and the decreased size of cloud-liquid particles which tend to increase cloud reflectivity is dominant over the enhanced size of cloud-ice particles which tends to decrease the reflectivity in the control run. This leads to a greater reflection of solar radiation and thereby larger upward SW over most of altitudes including the TOA in the control run as opposed to the single-moment run as shown in Fig. 8e. Figure 8e depicts the time- and area-averaged vertical distribution of upward SW for the control and single-moment runs. The control-run and single-moment-run upward TOA components of SW are larger and smaller than observed precipitation, respectively. However, the difference in the upward TOA component of SW between the control run and observation is smaller than that between the single-moment run and observation by $\sim 7 \mathrm{~W} \mathrm{~m}^{-2}$ (Table 2 ).

Less reflectivity of SW causes the downward surface (SFC) component of SW in the single-moment run to be correspondingly larger than that in the control run by $\sim 30 \mathrm{~W} \mathrm{~m}^{-2}$. The control-run downward SFC component of SW shows much better agreement with observed precipitation. The difference in the downward SFC component of SW between the control run and observation is only $\sim 9 \mathrm{~W} \mathrm{~m}^{-2}$ while the 
difference is $\sim 38 \mathrm{~W} \mathrm{~m}^{-2}$ between the single-moment run and observation (Table 2). The TOA upward component of longwave radiation flux $(\mathrm{LW})$ is larger in the single-moment run than in the control run by $\sim 16 \mathrm{~W} \mathrm{~m}^{-2}$, resulting in its larger difference between the single-moment run and observation than that between the control run and observed precipitation (Table 2). This is due to the smaller mass concentration of cloud liquid and cloud ice in the single-moment run than in the control run, which provides decreased absorption of infrared radiation emitted from the surface in the singlemoment run.

Also, it is worth pointing out that the predicted cloudliquid and -ice mass and size in the control run show larger vertical variations than those in the single-moment run as shown in Figs. 8a - d. The smaller vertical variations of the size in the single-moment run in contrast to the control run are due to the prescription of cloud-particle size in the singlemoment run. These larger vertical variations lead to a much larger vertical variation of radiation fluxes in the control run than in the single-moment run (for example, see Fig. 8e for the SW variation). This result indicates a large difference in the vertical distribution of radiatively driven atmospheric heating or cooling between the control and single-moment runs as shown in Fig. 8f; since the variation of fluxes is negligible above $12 \mathrm{~km}$, Fig. $8 \mathrm{f}$ depicts heating only up to $12 \mathrm{~km}$. The much larger vertical variation of fluxes leads to a much larger variation of the time- and area-averaged radiative heating (i.e., shortwave heating + longwave heating) in the control run than in the single-moment run in Fig. 8f. Note that the radiatively driven heating and cooling are proportional to the vertical gradient of radiation fluxes.

The time series of domain-averaged water path [i.e., LWP + ice water path (IWP)] shown in Fig. 9 indicates that the evolution of water path is significantly different between the control run and the single-moment run for both shallow and deep convection. Here, the LWP accounts for $\sim 90 \%$ of the water path. Although the single-moment run shows larger water path around 1730 UTC on 28 June and 2330 UTC on 29 June, the period during which the control-run water path is larger than the single-moment-run water path accounts for more than $\sim 65 \%$ of the whole period with nonzero water path. This is another indicative of larger TOA upward SW and smaller TOA upward LW in the control run than in the single-moment run.

\section{SUMMARY AND CONCLUSION}

The temporal evolution of precipitation rate in the simulation with the single-moment microphysics (the singlemoment run) was different from that with the double-moment microphysics (the control run). Generally, the control run showed a better agreement between the simulated and observed precipitation than the single-moment run. Precipitation differences between the single-moment run and the control run are strongly sensitive to the representation of key processes (i.e., autoconversion, saturation, and nucleation) was simulated. However, the precipitation differences between the single-moment run and the control run showed a negligible sensitivity to processes other than the key processes. This demonstrates that changes in the simulations of precipitation due to a migration from a single-moment microphysics to a double-moment microphysics are likely to be caused mostly by changes in the representation of the key processes and indicates that more attention needs to be paid to the framing of key processes for migration intended for the better simulation of precipitation.

Also, the dependence upon the role of the representation of the key processes in precipitation on a type of

Water path (ARM-A)

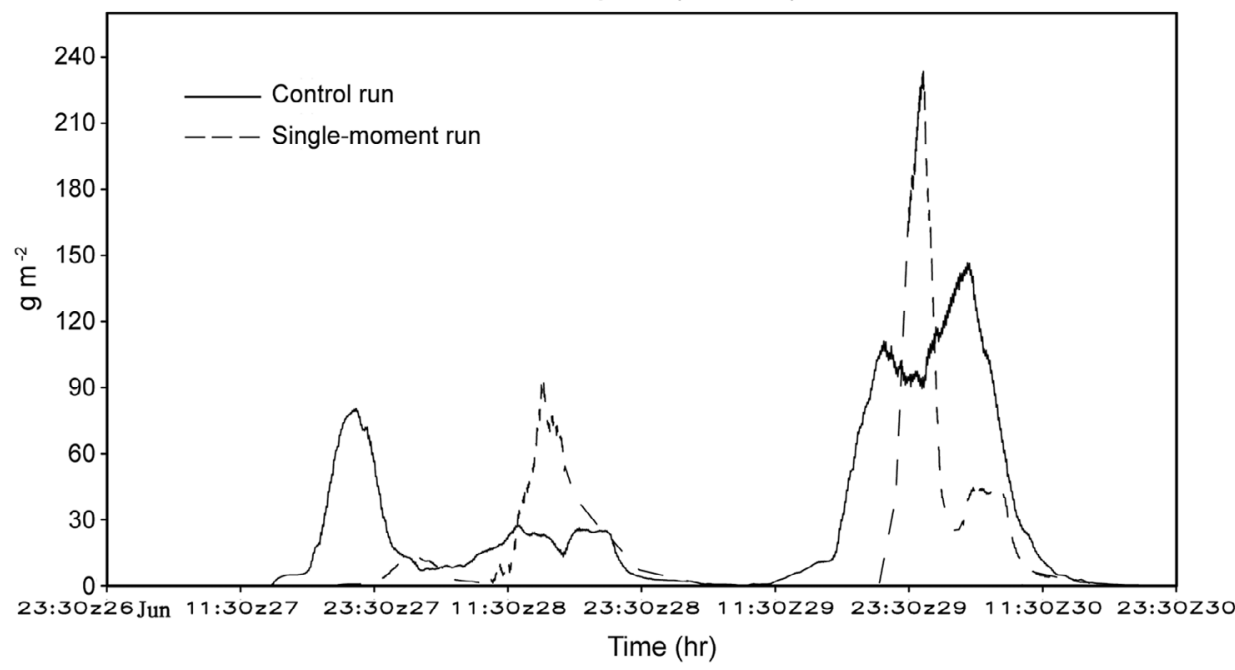

Fig. 9. Time series of the area-averaged water path in the control and single-moment runs for the ARM sub-case A. 
convection was simulated. The representation of autoconversion threshold (saturation and nucleation) played an important role in making the precipitation difference between the single- and double-moment microphysics in deep (shallow) convection but played a negligible role in shallow (deep) convection and indicates a need to differentiate the focus of the parameterization development based upon the type of convection in climate models. In regions of shallow convection such as trade cumuli, we need to focus primarily upon the representation of saturation and nucleation and do not have to focus so much upon the representation of the autoconversion threshold. However, in strong convection regions, we need to focus primarily on the representation of autoconversion threshold but less so on the saturation and nucleation.

The predicted size and mass of cloud particles in the control run better represented cloud radiative properties than the prescribed size and predicted mass of cloud particles in the single-moment run. Hence, there is a better agreement in the TOA and SFC radiative fluxes between the double-moment microphysics and observation than between the single-moment microphysics and observation. Also, the vertical distributions of cloud-particle mass and size and thus radiation fluxes simulated by the single-moment microphysics were significantly different from those evinced by the double-moment microphysics. The prescription of cloud-particle size in the single-moment microphysics was not able to emulate the large vertical variation of particle size simulated by the double-moment microphysics and led to the different radiative heating and cooling between the single- and double-moment microphysics. This result implies that the atmospheric instability induced by radiation is likely to be different between the single- and double-moment microphysics. The atmospheric instability affects hydrologic and dynamic circulations. A mesoscale convective system like the one simulated here is a building block of systems like the Asian and Indian Monsoon, storm tracks, and intertropical convergence zone. These systems play an important role in global hydrologic and energy circulations. Hence, the difference in heating and cooling by radiation (inducing that in the atmospheric instability) can lead to differences in global circulation patterns and thus in the assessment of the effect of clouds on climate between the single-moment and double-moment microphysics in climate models. The better representation of cloud radiative properties by the double-moment microphysics simulated here indicates that the effect of radiative heating and cooling on circulation patterns is likely to be better represented by the double-moment microphysics than by the single-moment microphysics.

As can be seen in Fig. 8c, the large portion of mass of cloud ice is concentrated around or above the level of homogeneous freezing (around $9-10 \mathrm{~km}$ ) where the conversion of cloud ice to precipitable snow is known to be very inefficient due to the absence of liquid-phase particles. Hence, although we assumed the collection efficiency of 1 for collisions between cloud ice and liquid-phase particles, just around $5 \%$ of the ice formed by deposition was converted into snow in this study. The low conversion efficiency of cloud ice, which is around $5 \%$, even with the collection efficiency of 1 demonstrates that there will be negligible changes in the mass of cloud ice with different crystal habits assumed. This indicates that results here are not likely to depend on the variation of conversion of ice crystals to snow due to the variation of an assumed crystal habit for collection processes. This study assumed the columnar shape of ice crystals for the characterization of the optical properties and thus calculation of radiative fluxes, following Phillips et al. (2007). Fu (2007) and Wendisch et al. (2007) demonstrated that the qualitative nature of the results of this study does not depend on this assumption.

In this study, the spectral information for riming is considered in the double-moment microphysics following Phillips et al. (2007) but not in the single-moment microphysics. Lee et al. (2010) showed that the consideration of spectral information does not affect the qualitative nature of results. This is because the riming is predominantly affected by the bulk property of cloud liquid, i.e., cloud-liquid mass, but not by the microphysical property of cloud liquid, i.e., cloud-liquid particle size. Hence, it is not likely that there is a strong dependence of results on the consideration of the spectral information for riming processes.

Acknowledgements The authors wish to thank Dr. Venkatachalam Ramaswamy for valuable discussions. This paper was prepared under award NA17RJ2612 from the National Oceanic and Atmospheric Administration, US Department of Commerce.

\section{REFERENCES}

Berezinskiy, N. A., G. V. Stepanov, and V. G. Khorguani, 1986: Altitude variation of relative ice-forming activity of natural aerosol. S. Meterol. Hydr., 12, 86-89.

DeMott, P. J., D. J. Cziczo, A. J. Prenni, D. M. Murphy, S. M. Kreidenweis, D. S. Thomson, R. Borys, and D. C. Rogers, 2003: Measurements of the concentration and composition of nuclei for cirrus formation. Proc. Natl. Acad. Sci. USA, 100, 14655-14660, doi: 10.1073/ pnas.2532677100. [Link]

Freidenreich, S. M. and V. Ramaswamy, 1999: A new multiple-band solar radiative parameterization for general circulation models. J. Geophys. Res., 104, 3138931409, doi: 10.1029/1999JD900456. [Link]

Fridlind, A., A. Ackerman, J. Petch, P. Field, A. Hill, G. McFarquhar, S. Xie, and M. Zhang, 2009: ARM/GCSS/ SPARC TWP-ICE CRM intercomparison study. Available at http://science.arm.gov/wg/cpm/scm/scmic6/in 
dex.html.

Fu, Q., 2007: A new parameterization of an asymmetry factor of cirrus clouds for climate models. J. Atmos. Sci., 64, 4140-4150, doi: 10.1175/2007JAS2289.1. [Link]

Georgii, H. W. and E. Kleinjung, 1967: Relations between the chemical composition of atmospheric aerosol particles and the concentration of natural ice nuclei. $J$. Rech. Atmos., 3, 145-156.

Hallet, J. and S. C. Mossop, 1974: Production of secondary ice particles during the riming process. Nature, 249, 26-28, doi: 10.1038/249026a0. [Link]

Hong, S. Y. and H. L. Pan, 1996: Nonlocal boundary layer vertical diffusion in a medium-range forecast model. Mon. Weather Rev., 124, 2322-2339, doi: 10.1175/152 0-0493(1996)124<2322:NBLVDI>2.0.CO;2. [Link]

Klemp, J. B., W. C. Skamarock, and J. Dudhia, 2007: Conservative split-explicit time integration methods for the compressible nonhydrostatic equations. Mon. Weather Rev., 135, 2897-2913, doi: 10.1175/MWR34 40.1. [Link]

Koop, T., B. Luo, A. Tsias, and T. Peter, 2000: Water activity as the determinant for homogeneous ice nucleation in aqueous solutions. Nature, 406, 611-614, doi : 10.1038/35020537. [Link]

Lee, S. S., L. J. Donner, V. T. J. Phillips, and Y. Ming, 2008: Examination of aerosol effects on precipitation in deep convective clouds during the 1997 ARM summer experiment. Q. J. R. Meteorol. Soc., 134, 1201-1220, doi: 10.1002/qj.287. [Link]

Lee, S. S., L. J. Donner, and J. E. Penner, 2010: Thunderstorm and stratocumulus: How does their contrasting morphology affect their interactions with aerosols? Atmos. Chem. Phys., 10, 6819-6837, doi: 10.5194/acp-106819-2010. [Link]

Liljegren, J. C., 1994: Two-channel microwave radiometer for observations of total column precipitable water vapor and cloud liquid water path. In: Proceedings of the $5^{\text {th }}$ Symposium on Global Change, 23-28 January 1994, Nashville, TN, USA, Am. Meteorol. Soc., Boston, MA, USA, 266-269.

Lin, Y. L., R. D. Farley, and H. D. Orville, 1983: Bulk parameterization of the snow field in a cloud model. $J$. Climate Appl. Meteorol., 22, 1065-1092, doi: 10.11 75/1520-0450(1983)022<1065:BPOTSF>2.0.CO;2. [Link]

Lohmann, U. and K. Diehl, 2006: Sensitivity studies of the importance of dust ice nuclei for the indirect aerosol effect on stratiform mixed-phase clouds. J. Atmos. Sci., 63, 968-982, doi: 10.1175/JAS3662.1. [Link]

Lohmann, U., P. Stier, C. Hoose, S. Ferrachat, S. Kloster, E. Roeckner, and J. Zhang, 2007: Cloud microphysics and aerosol indirect effects in the global climate model ECHAM5-HAM. Atmos. Chem. Phys., 7, 3425-3446. doi: 10.5194/acp-7-3425-2007. [Link]
Lord, S. J., H. E. Willoughby, and J. M. Piotrowicz, 1984: Role of a parameterized ice-phase microphysics in an axisymmetric nonhydrostatic tropical cyclone model. J. Atmos. Sci., 41, 2836-2848, doi: 10.1175/1520-0469 (1984)041<2836:ROAPIP>2.0.CO;2. [Link]

May, P. T., J. H. Mather, G. Vaughan, and C. Jakob, 2008: Characterizing oceanic convective cloud systems - The Tropical Warm Pool International Cloud Experiment. Bull. Amer. Meteorol. Soc., 89, 153-155, doi: 10.1175/ BAMS-89-2-153. [Link]

McFarquhar, G. M., A. J. Heymsfield, A. Macke, J. Iaquinta, and S. M. Aulenbach, 1999: Use of observed ice crystal sizes and shapes to calculate mean-scattering properties and multispectral radiances: CEPEX April 4, 1993, case study. J. Geophys. Res., 104, 3176331779, doi: 10.1029/1999JD900802. [Link]

Meyers, M. P., P. J. DeMott, and W. R. Cotton, 1992: New primary ice-nucleation parameterizations in an explicit cloud model. J. Appl. Meteorol., 31, 708-721, doi: 10. 1175/1520-0450(1992)031<0708:NPINPI>2.0.CO;2. [Link]

Michalakes, J., S. Chen, J. Dudhia, L. Hart, J. Klemp, J. Middlecoff, and W. Skamarock, 2001: Development of a next generation regional weather research and forecast model. In: Zwieflhofer, W. and N. Kreitz (Eds.), Developments in Teracomputing, Proceedings of the Ninth ECMWF Workshop on the Use of High Performance Computing in Meteorology, World Scientific, Singapore, 269-276.

Ming, Y., V. Ramaswamy, L. J. Donner, and V. T. J. Phillips, 2006: A new parameterization of cloud droplet activation applicable to general circulation models. $J$. Atmos. Sci., 63, 1348-1356, doi: 10.1175/JAS3686.1. [Link]

Morrison, H. and A. Gettelman, 2008: A new two-moment bulk stratiform cloud microphysics scheme in the community atmosphere model, version 3 (CAM3). Part I: Description and numerical tests. J. Climate, 21, 36423659, doi: 10.1175/2008JCLI2105.1. [Link]

Morrison, H., G. Thomson, and V. Tatarskii, 2009: Impact of cloud microphysics on the development of trailing stratiform precipitation in a simulated squall line: Comparison of one- and two-moment schemes. Mon. Weather Rev., 137, 991-1007, doi: 10.1175/2008MWR2556.1. [Link]

Möhler, O., P. R. Field, P. Connolly, S. Benz, H. Saathoff, M. Schnaiter, R. Wagner, R. Cotton, M. Krämer, A. Mangold, and A. J. Heymsfield, 2006: Efficiency of the deposition mode ice nucleation on mineral dust particles. Atmos. Chem. Phys., 6, 3007-3021, doi: 10. 5194/acp-6-3007-2006. [Link]

Phillips, V. T. J. and L. J. Donner, 2006: Cloud microphysics, radiation and vertical velocities in two- and three-dimensional simulations of deep convection. $Q$. 
J. R. Meteorol. Soc., 132, 3011-3033, doi: 10.1256/qj. 05.171. [Link]

Phillips, V. T. J., L. J. Donner, and S. T. Garner, 2007: Nucleation processes in deep convection simulated by a cloud-system-resolving model with double-moment bulk microphysics. J. Atmos. Sci., 64, 738-761, doi: 10. 1175/JAS3869.1. [Link]

Pruppacher, H. R. and J. D. Klett, 1978: Microphysics of Clouds and Precipitation, D. Reidel, 714 pp.

Salzmann, M., Y. Ming, J. C. Golaz, P. A. Ginoux, H. Morrison, A. Gettelman, M. Krämer, and L. J. Donner, 2010: Two-moment bulk stratiform cloud microphysics in the GFDL AM3 GCM: Description, evaluation, and sensitivity tests. Atmos. Chem. Phys., 10, 80378064, doi: 10.5194/acp-10-8037-2010. [Link]

Seinfeld, J. H. and S. N. Pandis, 1998: Atmospheric Chemistry and Physics: From Air Pollution to Climate Change, John Wiley \& Sons, 1326 pp.

Straka, J. M., M. S. Gilmore, K. M. Kanak, and E. N. Rasmussen, 2005: A comparison of the conservation of number concentration for the continuous collection and vapor diffusion growth equations using one- and two-moment schemes. J. Appl. Meteorol., 44, 18441849, doi: 10.1175/JAM2314.1. [Link]

Straka, J. M., K. M. Kanak, and M. S. Gilmore, 2007: The behavior of number concentration tendencies for the continuous collection growth equation using one- and two-moment bulk parameterization schemes. J. Appl. Meteorol. Climatol., 46, 1264-1274, doi: 10.1175/JAM 2527.1. [Link]

Wendisch, M., P. Yang, P. Pilewskie, 2007: Effects of ice crystal habit on thermal infrared radiative properties and forcing of cirrus. J. Geophys. Res., 112, D08201, doi: 10.1029/2006JD007899. [Link]

Whitby, K. T., 1978: The physical characteristics of sulfur aerosols. Atmos. Environ., 12, 135-159, doi: 10.10 16/0004-6981(78)90196-8. [Link]

Xu, K. M., R. T. Cederwall, L. J. Donner, W. W. Grabowski, F. Guichard, D. E. Johnson, M. Khairoutdinov, S. K. Krueger, J. C. Petch, D. A. Randall, C. J. Seman, W. K. Tao, D. Wang, S. C. Xie, J. J. Yio, and M. H.
Zhang, 2002: An intercomparison of cloud-resolving models with the atmospheric radiation measurement summer 1997 intensive observation period data. Q. J. R. Meteorol. Soc., 128, 593-624, doi: 10.1256/003590 002321042117. [Link]

\section{APPENDIX A}

Deposition nucleation at temperatures warmer than $-40^{\circ} \mathrm{C}$

At temperatures between -30 and $-40^{\circ} \mathrm{C}$ and between -5 and $-30^{\circ} \mathrm{C}$, DeMott et al. (2003, personal communication) and Meyers et al.'s (1992) parameterizations, multiplied by a scaling factor, are used for deposition nucleation, respectively. For temperatures between -30 and $-40^{\circ} \mathrm{C}$ :

$N_{I N}\left(m^{-3}\right)=1000\left\{\exp \left[12.96\left(S_{i}-1.1\right)\right]\right\}^{0.3} \times \Psi$

Here, $N_{I N}$ is ice-crystal number concentration, $S_{i}$ the saturation ratio with respect to ice and $\Psi$ a scaling factor to take into account the dependence of $I N$ activation on dust mass concentration. $\Psi$ is $D U_{2.5} / D U_{2.5}^{*}$, where $D U_{2.5}$ is mass concentration of dust particles with diameter less than $2.5 \mu \mathrm{m}$ and $D U_{2.5}^{*}$ is a reference dust mass concentration. $D U_{2.5}^{*}$ is set at $0.11 \mu \mathrm{g} \mathrm{m}^{-3}$ based on dust data from the Mount Werner project used to derive (A1) (DeMott et al. 2003, personal communication). Hence, (A1) computes $N_{I N}$ based on variation of dust-mass concentration relative to dust-mass concentration observed at the Mount Werner project. It was observed that $I N$ concentrations were almost linear with the concentrations of large aerosol particles (Georgii and Kleinjung 1967; Berezinskiy et al. 1986), supporting the assumption that $N_{I N}$ is proportional to $D U_{2.5}$. For temperatures between -5 and $-30^{\circ} \mathrm{C}$, the same scaling factor as used in (A1) is applied to Meyers et al.'s (1992) parameterization as follows, since the data of dust-mass concentration are not available in Meyers et al. (1992):

$N_{I N}\left(m^{-3}\right)=1000 \exp \left[12.96\left(S_{i}-1\right)-0.639\right] \times \Psi$ 